\title{
Adıyaman ilinde Tüketime Sunulan Tavuk Etlerinde Salmonella Spp. Yaygınlığının Son Zamanlarda Geliştirilen Biotinil-Tiramid Yöntemi ile Belirlenmesi
}

\author{
Muhsin AYDIN ${ }^{1^{*}}$ \\ ${ }^{1}$ Adıyaman Üniversitesi, Fen Edebiyat Fakültesi, Biyoloji Bölümü, 02040, Adıyaman, TÜRKIYE \\ (ORCID: http://orcid.org/0000-0002-1204-1163) \\ "Sorumlu yazar: muhsin.aydin@live.com.
}

Öz

Dünya genelinde, Salmonella spp. nörovirüslerden sonra en fazla besin zehirlenmesine sebebiyet veren patojenik bakterilerdir. Salmonella cinsine ait 2600 'den fazla serovar tanımlanmış olup, bu cinse ait serovarların en çok tercih ettiği konak kanatlı hayvanlardır. Dolayısıyla, Salmonella cinsine ait serovarlarının sebebiyet verdiği gıda zehirlenmelerinin en yaygın olanı kümes hayvanları etlerinin (özellikle tavuk eti ve bu etin kullanıldığı mamullerin) tüketilmesiyle ortaya çıkmaktadır. Bu çalışmada Adıyaman Ili'nde tüketime sunulan kümes hayvanı (tavuk) etlerinde Salmonella cinsine ait bakterilerin yaygınlığının belirlenmesi amaçlanmıştır. Bu amaç için Salmonella spp.'ye spesifik olarak bağlanabilen manyetik mikro boncuklar kullanılmış ve immünomanyetik separasyon (IMS) yapılarak bakteriler izole edilmiştir. Daha sonra tiramid amplifikasyonu (TA) yardımı ile bu patojenik bakterilerin kanatlı etlerindeki bulunma oranları belirlenmiştir. Bu çalışmada perakende olarak satılan tavuk etlerinden rastgele olarak seçilen 124 örnek çalışılmış ve bunların 35 (\% 28.23) adedinde Salmonella spp.'ye rastlanılmıştır.

Anahtar Kelimeler: Salmonella, Biyotin, Kanatlı etleri, Manyetik boncuklar, Sinyal amplifikasyonu.

\section{Determinaton of Salmonella spp. Prevalence by a Recently Developed Biotinyl- Tyramide Signal Amplification from Retailed Poultry Meat in Adıyaman Province}

\begin{abstract}
Worldwide, species belonging to the genus Salmonella are pathogenic bacteria and are the second most food poisoning causative agents after noroviruses. More than 2600 serovar of Salmonella have been defined, and their primary reservoir is poultry. Therefore, salmonellae serovars are most frequently associated with consumption of poultry meat and poultry products, which leads to Salmonella-related foodborne illnesses. The main purpose of this study was to determine the prevalence of Salmonella spp. by use of biotinyl-tyramide signal amplification from retail poultry (chicken) meat in Adıyaman province. For this purpose, magnetic micro-beads which can specifically bind to Salmonella spp., was used for isolation by applying Immunomagnetic Separation (IMS), and Tyramide Amplification (TA) was used for detection of the bacteria in order to determine the presence (by ratio) of Salmonella spp. in poultry meat. In this study, 124 samples of poultry meat were studied and 35 (28.23\%) of them were Salmonella positive.
\end{abstract}

Key Words: Salmonella, Biotin, Poultry, Magnetic beads, Signal amplification. 
Giriş

Salmonella, Enterobacteriaceae familyasına ait en önemli cinlerden biridir. Bu bakteriler basil şeklinde, spor üretmeyen, fakültatif anaeroblar olup Gram negatiftirler. Salmonella cinsine ait 2 tür, 6 alttür ve 2500'den fazla serovar tespit edilmiştir (Porwollik ve ark., 2004; Grimont ve Weill, 2007). Salmonella kemoorganotrofik bir organizma olarak sınıflandırılmış olup çok geniş bir yelpazede yer alan organik substratları solunum ya da fermentasyon yoluyla metabolize edebilen bir canlıdır (Monadi ve ark., 2010; Dos Santos ve ark., 2011). Salmonella'nın optimal büyüme sıcaklığı $37^{\circ} \mathrm{C}$ olup insan vücut Isısına eşit değerdedir. Aynı zamanda düşük $\mathrm{pH}$ ve çok az miktarda besin bulunması durumları da dahil olmak üzere ekstrem çevre koşullarında dahi yaşamını devam ettirebilir (Kwon ve Ricke, 1998; Durant ve ark., 1999; Ricke, 2003a; Ricke 2003b). Hatta bazı Salmonella suşları 2 ila $4^{\circ} \mathrm{C}^{\prime} \mathrm{de}$ büyüme yeteneğine sahip iken bazı suşları $54^{\circ} \mathrm{C}^{\prime}$ deki sıcak ortamlarda dahi yaşamlarını devam ettirebildikleri belirtilmiştir (Balamurugan, 2010). Salmonella kaynaklı enfeksiyolar insan ve hayvan sağlığına önemli derecede etki etmektedir. Salmonella'nın birçok formu antibiyotiklere karşı direnç geliştirmiştir. Bu nedenle, Salmonella kaynaklı ilerlemiş enfeksiyonların antibiyotiklerle durdurulması gün be gün daha zor hale gelmiştir. Günümüze dek, 200'den fazla virüs, bakteri ve parazit dahil olmak üzere gıda kaynaklı hastalıklara neden alan patojen tanımlanmıştır (Tauxe,
2002; Scallan ve ark., 2011). The Centers for Disease Control and Prevention (CDC, Hastalık Kontrol ve Önleme Merkezleri) sadece Amerika Birleşik Devletleri'nde gıda kaynaklı 128.000'in üzerinde hastalık vakasının ve 3.000 'in üzerinde ölümün meydana geldiğini rapor etmiştir. Bu vakaların \%11'inin de Salmonella spp.'den kaynaklandığını ortaya çıkarmıştır. Ayrıca, CDC'nin yapmış olduğu araştırmalara göre son 5 yılda Salmonella etkenine bağlı gıda kaynaklı ölüm sayılarının 320'den 380'e çıktığı saptanmıştır (CDC-FoodNet, 2009; Scallan ve ark., 2011; CDC, 2017). Bu yüzdelik dilim ile Salmonella spp. nörovirüslerden sonra en fazla besin zehirlenmesine sebep olan patojen olmuştur, aynı zamanda bu rakamlarla en çok besin zehirlenmesine sebep olan bakteriler arasında ilk sırayı almıştır. Ayrıca, kümes hayvanları, Salmonella türlerini doğal olarak mide-bağırsak sistemlerinde taşımalarından dolayı, bu hayvanlar Salmonella türlerinin insanlara geçişinde birincil derecede rol oynamaktadırlar.

Türkiye'de görülen gıda kaynaklı enfeksiyonlar hakkında yeterli veri bulunmamakla beraber Salmonella spp.'nin neden olduğu vaka sayısı en son Türkiye İstatistik Kurumu (TÜiK) tarafından 2004 yılında verilmiştir. Bu verilere göre 4.135 kişinin Salmonella nedeniyle hastanede tedavi gördüğü ve 35 kişinin hayatını kaybettiği bildirilmiştir (GGD, 2013). Bu sebeple, Salmonella türlerinin besinlerde ve özellikle de kanatlı etleri ve bunların kullanıldığı mamullerde taramasının yapılması gıda 
hijyeni konusunda önemli bir gereklilik teşkil etmektedir.

Salmonella türlerinin sebep olduğu hastane vakaları ve ölüm sayıları göz önünde bulundurularak gıdalarda ve gıda yüzeylerinde, özellikle de kanatlı etleri ve mamullerinde patojen taraması ve bu patojenlerin sayımı gıda güvenliği ve hijyeni açısından son derece büyük önem arz etmektedir. Hükümet yetkilileri ve gıda şirketleri ürünlerin tüketime sunulmasındaki her aşamada kontaminasyon durumlarını izlemek için mikrobiyolojik analiz yöntemleri kullanırlar. Tehlike Analizi ve Kritik Kontrol Noktaları (Hazard Analysis and Critical Kontrol Points $=$ HACCP) sistemi göz önünde bulundurularak her besin için uygun mikrobiyolojik yöntemin seçilmesi şarttır (Stannard, 1997; Jasson ve ark., 2010; Park ve ark., 2014). Bu sistem, ürün güvenliğini etkileyen tehlikelerin önceden belirlenmesi ve kontrol altına alınmasını sağlayan sistematik bir yaklaşımdır. HACCP gibi kontaminasyon önleyici sistemlerin uygulanması gıda güvenliğini arttırmıştır, fakat daha iyi patojen tarama yöntemleri geliştirilene kadar HACCP tam olarak etkili olamayacaktır (Bhunia, 2008). Bu nedenle, HACCP ile entegre olarak çalışabilecek patojen tarama ve tanımlama hususunda etkili olabilecek yeni teknolojilerinin geliştirilmesi elzem olmuştur. Bu çalışmada yapılan immünomanyetik separasyon (IMS) tabanlı tiramid amplifikasyonunun (TA) Salmonella türlerinin kanatlı etlerinde varlıklarının belirlenmesi son yıllarda revaçta olan bir yaklaşımdır (Aydin ve ark., 2014; Herzig ve ark., 2016).

Salmonella cinsine ait bakteri türlerinin günümüze dek dünya üzerinde sebep oldukları besin zehirlenmelerinin sayısı çok fazla olmakla beraber yıllık on milyonlarla hesaplanmaktadır (Scallan ve ark., 2011). Bu sayılar, söz konusu olan patojen bakteri türlerinin gıda hijyeni açısından ne kadar önem taşıdığını göstermektedir. Ülkemizde, gıdalarda Salmonella spp. etkenlerinin bulunma sıklıklarına ve Salmonella spp. ile kontamine olmuş gıdalarının tespitine dair yapılan çalışma sayısı oldukça azdır. Bununla birlikte, Adıyaman sınırları içerisinde bu çalışmaya benzer herhangi bir çalışma yapılmadığına rastlanılmıştır. $\mathrm{Bu}$ çalışmanın ana amacını Adıyaman İli'nde tüketime sunulan tavuk etlerinde Salmonella spp.'nin yaygınlığının IMS-TA metodu ile belirlenmesi oluşturmuştur.

\section{Materyal ve Metot}

\section{Örneklerin toplanması}

Adıyaman ìli sınırları içerisinde bulunan tavuk eti satan yerel marketlerden rastgele tavuk but, göğüs, baget vs. gibi ürünler toplanmıştır.

\section{Kullanılan bakterilerin temini}

Testlerde pozitif kontrol olarak kullanılan Salmonella cinsine ait örnekler, Mustafa Kemal Üniversitesi Fen-Edebiyat Fakültesi Biyoloji Bölümü'nden temin edilmiştir. 
Bakteri kültürlerinin hazırlanması ve büyüme koşulları

Pozitif Kontrol olarak kullanılan bakteriler, cam tüp içerisinde $5 \mathrm{~mL}$ olarak bulunan triptik soy broth (TSB) içerisine konulmuş ve $37^{\circ} \mathrm{C}^{\prime}$ de 18 saat inkübe edilmiştir. Daha sonra inkübe edilen bu tüpler seri dilüsyonla $10^{-6,} \mathrm{e}$ kadar seyreltilmiş olup son dilüsyondan $100 \mu \mathrm{L}$ bakteri kültürü alınıp triptik soy agar (TSA) üzerine konulmuş ve " $\mathrm{L}$ " şeklindeki yayıcı yardımıyla besiyeri yüzeyine dağıtılmıştır (bu işlem 3 farklı Petri kabına uygulandı). Daha sonra bu besiyerleri $37^{\circ} \mathrm{C}^{\prime}$ de 18 saatlik inkübasyona bırakılmışlardır. İnkübasyondan sonra her bir Petri kabındaki koloniler sayılmış ve 3'e bölünerek mL'deki KOB (koloni oluşturan birim) yani yaklaşık bakteri sayısı belirlenmiştir.

\section{Gıda örneklerinin hazırlanması}

Tavuk etleri her analizden 24 saat önce rastgele toplanmıştır. Her bir örnekten $25 \quad \mathrm{~g}$ alınıp $225 \mathrm{~mL}$ tamponlanmış peptonlu su (TPS) içerisine konulup stomacher yardımıyla homojenize edilmiş ve $37^{\circ} \mathrm{C}^{\prime}$ de 3 saat inkübe edilerek bir ön zenginleştirme işlemi yapılmıştır. Pozitif kontroller için hazırlanan homojenatların 6 adedine farklı dilüsyonlarda $\left(3 \times 10^{1}-3 \times 10^{6} \mathrm{KOB}\right)$ Salmonella spp. inoküle edilmiştir. Bu şekilde, kontamine edilen tavuk eti homojenatlarında IMS-TA testinin hassasiyeti de hesaplanmıştır.

Deneysel olarak kontamine edilen ve perakende olarak alınan örneklerin IMSTA ile test edilmesi
Bu analiz daha önce Aydın ve ark. (2014)'te belirtmiş olduğu yöntemle yapılmıştır. Kısaca, 96-kuyucuklu mikroplakaların her bir kuyucuğuna $3 \mu \mathrm{L}$ anti-Salmonella antikorlarıyla kaplanmış olan immünomanyetik boncuklardan (IMB) (Dynabeads ${ }^{\circledR}$ anti-Salmonella, Life Technologies, Carlsbad, CA) konulmuştur. Her bir örnek üçlü kopyalar (triplicate) şeklinde test edilmiştir. Daha sonra üzerlerine her numuneden $100 \mu \mathrm{L}$ eklenip oda ısısında 30 dakika yavaş moddaki çalkalayıcıya yerleştirildi. İçine homojenat konulmayan IMB'ler negatif kontrol olarak kullanılmıştır. İnkübasyon işlemi sonucunda oluşacan IMBSalmonella kompleksleri $1 \mathrm{dk}$ mıknatıs üzerinde tutulup $150 \mu \mathrm{L}$ TNT buffer (0.1 $\mathrm{M}$ Tris $-\mathrm{HCl}, 0.15 \mathrm{M} \mathrm{NaCl}$ ve $0.05 \%$ Tween 20, $\mathrm{pH}$ 7.5) ile yıkanmıştır. $\mathrm{Bu}$ işlem üç defa tekrar edilmiştir. TA için ELAST ELISA Amplification System (Perkin Elmer, Waltham, MA) kiti üretici firmanın direktifleri doğrultusunda kullanılmıştır. TNT ile yıkanan örnekler $100 \mu \mathrm{L}$ (Horse radish peroxidase, kit içerisinde mevcut) ile etiketlenmiş anti-Salmonella antikorları eklenmiş ve numuneler oda ısısında 30 dakika çalkalayıcı üzerinde inkübe edilmiştir. Daha sonra örnekler, mıknatıs ve TNT yardımıyla 3 defa yıkanmıştır. Akabinde, $50 \mu \mathrm{L}$ biotiniltiramid solüsyonu $50 \mu \mathrm{L}$ sulandırıcı (kit içerisinde mevcut) ile süspanse edilmiş ve her kuyucuğa toplam $100 \mu \mathrm{L}$ şeklinde eklenmiştir. Numuneler, oda Isısında yavaş modda çalışan çalkalayıcı üzerinde $10 \mathrm{dk}$ inkübe edilmiştir. Yıkama işlemi aynı şekilde 3 defa tekrarlanmıştır. Daha sonra her örneğe $10 \mu \mathrm{g} \mathrm{mL}^{-1}$ 
Streptavidin-Cy3 (Sigma, GER) eklenmiş ve oda Isısında $30 \mathrm{dk}$ inkübe edilip $150 \mu \mathrm{L}$ TNT ile 3 defa yıkanmıştır. Yıkamadan sonra $150 \mu \mathrm{L}$ TNT eklenip örneklerde bulunan sinyal miktarı floresan mikroplaka okuyucu ile belirlenmiştir.

\section{Data Analizi}

Streptavidine bağlı olan Cy3'ün yansıttı̆̆ı floresan miktarı floresantabanlı mikroplaka okuyucuda (Thermo Scientific, Watertown, MA) belirlendikten sonra elde edilen veri, okuyucuya bağlı bilgisayar tarafından MS Excel (Microsoft, Redmond, WA) dosyası olarak kaydedilmiştir. Üçlü kopyalar halinde test edilen numunelerin ortalamaları ve standart sapmaları hesaplanmıştır. Daha sonra negatif kontrol olarak kullanılan örnekler (içerisinde bakteri bulunmayan) arka plan olarak kullanılmıştır. Gerçek floresan miktarı numunelerin ortalamalarından elde edilen floresanın negatif kontrol (NK) ortalamasından çıkarılması yoluyla net floresan sinyalleri her bir örnek ve dilüsyon (pozitif kontroller) için ayrı ayrı hesaplanmıştır. Elde edilen net sinyaller, negatif kontrole ait sinyal değerinin en az üç katı olan numunelerde Salmonella varlığının olduğuna karar verilmiştir.

\section{Araştırma Bulguları ve Tartışma}

Bu çalışmada, Adıyaman'da tavuk eti örneklerinde Salmonella spp. taraması yapılmış ve bu bölgede söz konusu bakterilere ait bir istatistik oluşturulması aşamasında yapılan ilk çalışmalardan biri olmuştur.
$\mathrm{Bu}$ çalışmada Salmonella cinsine ait türlerin tavuk etlerindeki varlık tespitleri IMS-TA yöntemiyle belirlenmiş olup bu testin hassasiyeti testlere başlanmadan önce pozitif kontrol kullanılarak tespit edilmiştir (Şekil 1). Lineer regresyon eğrisinde oluşan $R^{2}$ değerinin 0.9964 olduğu ortaya konulmuştur. $R^{2}$ değeri 1 'e yaklaştıkça bu testin güvenilirliğinin de arttığı ve hedef alınan herhangi bir patojenin gıdalardaki taramasında kullanılabileceği anlamlarına gelmektedir (Aydın ve ark., 2014).

Negatif kontrolün 3 katından büyük olan (net sinyal $>3 \times N K$ ise pozitif) herhangi bir net sinyal pozitif olarak kabul edilmiştir. Yani yapılan analizin hassasiyet barajı (deteksiyon limiti (DL)), $3 \times 699.3=2097.9$ olmuştur (Çizelge 1) . $\mathrm{Bu}$ rakamdan büyük olan bütün net sinyaller pozitif olarak değerlendirilmiş olup elde edilen sonuçlara göre test edilen bütün dilüsyonlar pozitif sonuç vermiştir. Sonuçlara bakıldığında en küçük dilüsyon olan $30 \mathrm{KOB} \mathrm{mL}^{-1}$ nin dahi pozitif olduğu gözlemlenmiştir. Buna göre $\mathrm{mL}$ 'sinde $30 \mathrm{KOB}$ içeren dilüsyon çalışmamızın hassasiyet limiti olarak belirlenmiştir. Aydın ve ark. (2014) aynı metodu kullanarak deneysel olarak kontamine ettikleri süt ve kıyma örneklerinde E. coli 0157:H7 taraması yapmışlar ve 3 saatlik bir ön zenginleştirme aşaması olmaksızın testlerinin hassasiyetini sırasıyla süt için $250 \mathrm{KOB} \mathrm{mL} \mathrm{L}^{-1}$ ve kıyma için $100 \mathrm{KOB} \mathrm{mL} \mathrm{m}^{-1}$ şeklinde bulmuşlardır (Aydın ve ark., 2014). Ayrıca, bu araştırmacılar 3 saatlik bir ön zenginleştirme aşaması ekleyerek IMS-TA testinin hassasiyetinin 10 kata 
kadar arttığını hesaplamışlardır. Diğer benzer bir çalışmada, Herzig ve ark. (2016) aynı IMS-TA metodunu uygulamış ve deneysel olarak çeşitli dilüsyonlarda kontamine ettikleri kıyma ile tavuk etlerinde Salmonella taraması yapmışlardır. Araştırmacıların bulmuş olduğu hassasiyet ölçümü sonuçları kıyma ve tavuk etlerinde sırasıyla 800 ve $200 \mathrm{KOB} \mathrm{mL}^{-1}$ şeklindedir. Yapılan bu çalışmadaki hassasiyet testi sonuçları, bu çalışmanın daha önce yapılan benzer çalışmalardan 7 kat daha hassas olduğunu göstermektedir. Önceki çalışmalarda belirtilmiş olduğu üzere 12 saatlik bir ön zenginleştirme aşamasının IMS-TA testinin hassasiyetini oldukça geliştirdiği (1 KOB $\mathrm{mL}^{-1}$ ) belirlenmiştir. Yapılan bu çalışmada $6-12$ saatlik ön zenginleştirme aşamaları IMS-TA testini daha kısa sürede sonuç verebilmesi ve testin aynı gün içerisinde sonuçlandırılabilmesi amacıyla denenmemiştir. Çünkü bakterilerin üreme hızının çok kısa sürelidir. Bu da, bu çalışmada daha kısa süreli (3 saat) ön zenginleştirme aşaması ile benzer sonuçların alınabileceğine işaret etmektedir.

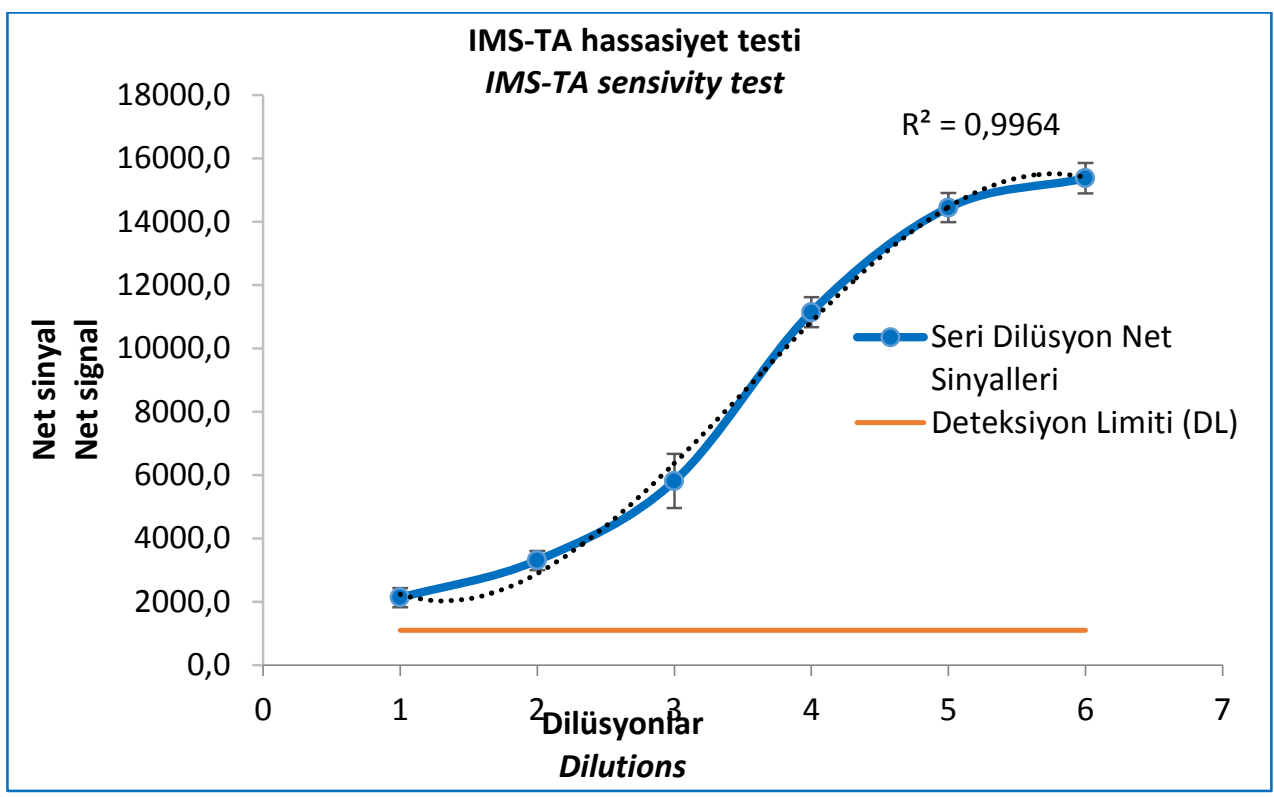

Şekil 1. IMS-TA hassasiyet testi sonuçları

Figure 1. IMS-TA sensitivity test results

Bu çalışmada, toplanan 124 tavuk eti örneğinin $35 \quad$ (\%28.23) adedinde Salmonella spp.'ye rastlanılmıştır. IMS-TA yöntemiyle çalışılan bu örneklerden elde edilen sonuçlar aynı zamanda ABD Gıda ve Ilaç Yönetimi (US Food and Drug Administration - FDA)'nin belirlemiş olduğu bakteriyolojik analiz kılavuzuna (Bacteriological Analytical Manual- BAM) göre uygulanan klasik kültür tekniği ile de doğrulanmıştır. Klasik mikrobiyolojik kültür teknikleri yardımıyla tavuk etlerinde Salmonella spp. taraması yaklaşık olarak 5 ila 7 gün 
sürebilmektedir (BAM, 1998). Bu da, IMSTA'nın klasik mikrobiyolojik testlere göre daha pratik, daha ucuz ve çok daha kısa sürede sonuç verebilen bir tarama yöntemi olduğunu kanıtlamaktadır.

Çizelge 1. IMS-TA hassasiyet testi sonuçları (sinyal değerleri). NK: negatif kontrol; KOB: Koloni oluşturan birim

Table 1. IMS-TA sensitivity test results (signal values). NC: negative control; CFU: Colony forming units

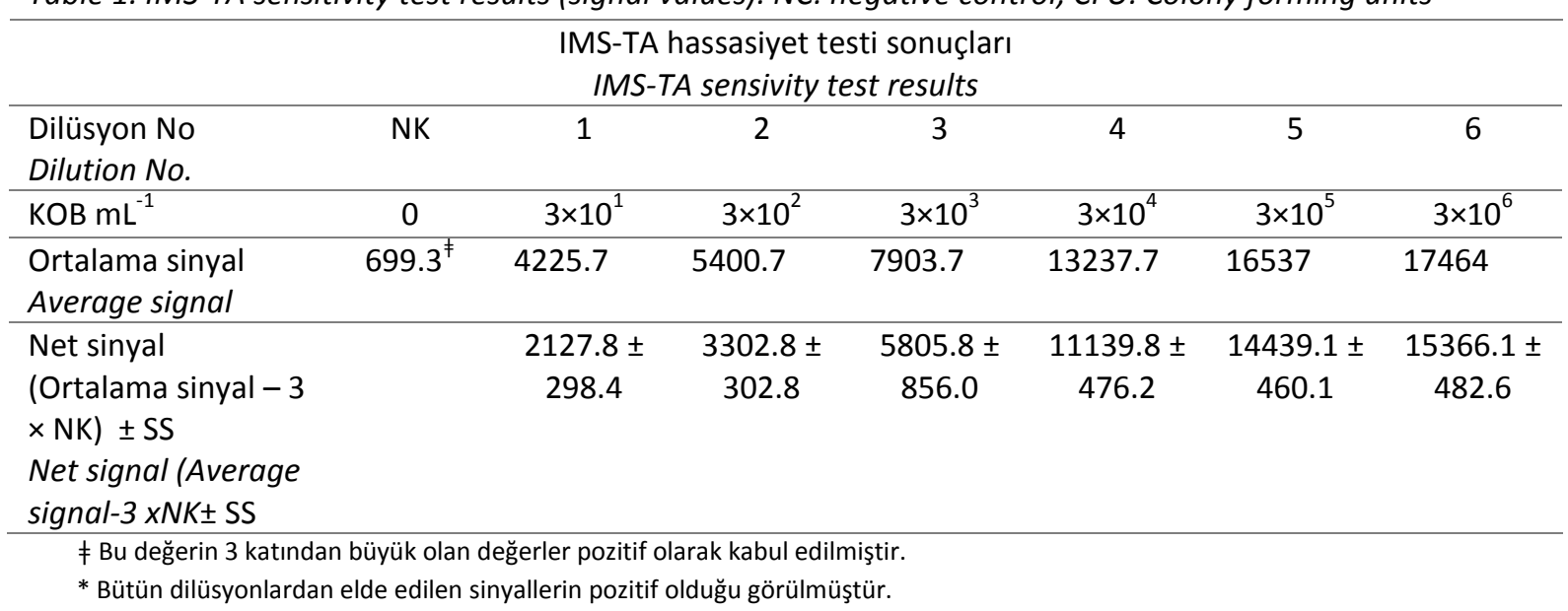

Daha önce yapılan benzer çalışmalarda, Aydın ve ark. (2014) ve Herzig ve ark. (2016) IMS-TA yöntemi ile deneysel olarak kontamine edilen gıda ürünlerinde mikroorganizma taraması yapmışlardır. Bu çalışmada ise deneysel olarak kontamine edilen tavuklarda Salmonella spp. taramasının yanında tavuk etlerinde var olan Salmonella spp.'nin bulunma oranları da araştırılmıştır. Bu sayede çalışmamız bu alanda ilkler arasında yer almaktadır.

Sonuç olarak, tiramid sinyal amplifikasyonu yöntemi ile yapılacak olan doğru ve kısa süreli patojenik bakteri tanımlamalarının, kontamine olmuş kümes hayvanı eti ve mamullerini tüketen şahısların erken uyarılması ile besin zehirlenmelerinin önüne geçilebileceği öngörülmektedir. Aynı zamanda, bu tekniğe ilaveten çeşitli moleküler tekniklerin (PCR, NGS,
Microarray, vb.) kullanılması ile gıda zehirlenmesi geçiren hastaların hangi patojen tarafından zehirlendiğinin kesin ve hızlı bir şekilde belirlenerek doğru tedavi verilmesi sağlanması amaçlanmakta olup halk sağığının korunabileceği ve besin zehirlenmelerinden kaynaklı ekonomik kayıpların önlenebileceği düşünülmektedir.

\section{Kaynaklar}

Aydin, M., Herzig, G.P.D., Jeong, K.C., Dunigan, S., Shah, P., Ahn, S. 2014. Rapid and sensitive detection of Escherichia coli 0157:H7 in milk and ground beef using magnetic bead-based immunoassay coupled with tyramide signal amplification. Journal of Food Protection, 77 (1): 100-105.

Balamurugan, S. 2010. Growth temperature associated protein expression and membrane fatty acid composition profiles of Salmonella enterica serovar Typhimurium. Journal of Basic Microbiology, 50: 507-518. 
BAM. 1998. (Bacteriological Analytical Manual), 8th Edition, Revision A, 1998. Chapter 4. http://www.fda.gov/Food/FoodScienceRe search/LaboratoryMethods/ucm070149.h tm. Erişim tarihi: 27.10.2016.

Bhunia, A.K. 2008. Foodborne microbial pathogens. Springer Science+Business Media, LLC, New York, NY, 158p.

CDC-FoodNet. (2009). Preliminary FoodNet data on the incidence of infection with pathogens transmitted commonly through food - 10 states, 2009. MMWR, 59, 418422.

CDC (Centers for Disease Control and Prevention). (2017). https://www.cdc.gov/foodborneburden/P DFs/pathogens-complete-list-01-12.pdf. Erişim tarihi: 30.06.2017.

Dos Santos, S.A., De Andrade, Jr. D.H., De Andrade, D.R. 2011. TNF-a production and apoptosis in hepatocytes after Listeria monocytogenes and Salmonella Typhimurium invasion. Revista do Instituto de Medicina Tropical de Sao Paolo, 53: 107-112.

Durant, J.A., Corrier, D.E., Byrd, J.A., Stanker, L.H., Ricke, S.C. 1999. Feed deprivation affects crop environment and modulates Salmonella enteritidis colonization and invasion of Leghorn hens. Applied Environmental Microbiology, 65: 19191923.

GGD (Gıda Güvenliği Derneği). 2013. Gıda kaynaklı Salmonella infeksiyonları ve son durum.

http://www.ggd.org.tr/icerik.php?id=462. Erişim tarihi: 18.11.2016

Grimont, P.A.D., Weill, F.X. 2007. Antigenic formulae of the Salmonella serovars, ninth ed. Institut Pasteur, Paris.

Herzig, G.P.D., Aydin, M., Dunigan, S., Shah, P., Jeong, K.C., Park, S.H., Ricke, S.C., Ahn, S. 2016. Magnetic bead-based immunoassay coupled with tyramide signal amplification for detection of Salmonella in foods. Journal of Food Safety, 36: 383-391.

Jasson, V., Jacxsens, L., Luning, P., Rajkovic, A., Uyttendaele, M. 2010. Alternative microbial methods: An overview and selection criteria. Food Microbiology, 27: 710-730.

Kwon, Y.M., Ricke, S.C. 1998. Induction of acid resistance of Salmonella Typhimurium by exposure to short-chain fatty acids. Applied Environmental Microbiology, 64: 3458-0463.

Monadi, A.R., Mirzaei, H., Javadi, A., Hosseinzade, N., Amjadi, Y. 2010. Effects of some probiotics on Salmonella Typhi during associated growth in milk. African Journal of Microbiology Research, 4: 2708-2711.

Park, S.H., Aydin, M., Khatiwara, A., Dolan, M.C., Gilmore, D.F., Bouldin, J.L., Ahn, S., Ricke, S.C. 2014. Current and emerging technologies for rapid detection and characterization of Salmonella in poultry and poultry products. Food Microbiology, 38: 250-262.

Porwollik, S., Boyd, E.F., Chay, C., Cheng, P., Florea, L., Proctor, E., McClelland, M. 2004. Characterization of Salmonella enterica subspecies I genovars by use of microarrays. Journal of Bacteriology, 18: 5883-5898.

Ricke, S.C. 2003a. Perspectives on the use of organic acids and short chain fatty acids as antimicrobials. Poultry Science, 82: 632639.

Ricke, S.C. 2003b. The gastrointestinal tract ecology of Salmonella Enteritidis colonization in molting hens. Poultry Science, 82: 1003-1007.

Scallan, E., Hoekstra, R.M., Angulo, F.J., Tauxe, R.V., Widdowson, M.A., Roy, S.L., Jones, J.L., Griffin, P.M. 2011. Foodborne illness acquired in the United States-major pathogens. Emerging Infectious Diseases, 17: 7-15.

Stannard, C. 1997. Development and use of microbiological criteria for foods. Food Science Technology Today, 11: 137-177.

Tauxe, R.V. 2002. Emerging foodborne pathogens. International Journal of Food Microbiology, 78: 31-41. 